\title{
REVIEW
}

\section{Drug-resistant tuberculosis in the 1990s}

\author{
W.W. Yew, C.H. Chau
}

\begin{abstract}
Drug-resistant tuberculosis in the 1990s. W.W. Yew, C.H. Chau. CERS Journals Ltd 1995. ABSTRACT: There has been an upsurge of tuberculosis in many parts of the world in the past decade. The high rates of drug-resistant tuberculosis currently reported in many countries are alarming. The most catastrophic phenomenon is the emergence of multidrug-resistant strains of Mycobacterium tuberculosis. These organisms have caused epidemic outbreaks in nosocomial and health-care settings in the USA and some European countries. In addition to immigration, poverty, alcoholism and intravenous substance abuse, human immunodeficiency virus (HIV) infection has also had a significant impact on the prevalence of drug resistance, since amongst these patient groups a common factor giving rise to drug resistance is noncompliance.

Rapid drug susceptibility tests are needed, and effective chemotherapy regimens with newly developed drugs in combination with traditional second-line antituberculosis agents for established multidrug-resistant tuberculosis are urgently being sought. There is also a quest for other novel modalities of therapy. Measures should be actively adopted to prevent the development of drug resistance. Well formulated short-course chemotherapy as initial treatment and ensurance of compliance are the most important components. The organization of a national tuberculosis control programme with a sound and adequately functioning infrastructure remains the most effective strategy to combat the resurgence of tuberculosis and to curtail drug resistance.
\end{abstract}

Eur Respir J., 1995, 8, 1184-1192.

Tuberculosis \& Chest Unit, Grantham Hospital, Aberdeen, Hong Kong.

Correspondence: W.W. Yew Tuberculosis \& Chest Unit Grantham Hospital 125 Wong Chuk Hang Road Aberdeen

Hong Kong

Keywords: Drug-resistant tuberculosis epidemiology and mechanisms rapid diagnosis treatment modalities

Received: July 261994

Accepted after revision February 191995
The World Health Organization and the US Centers for Disease Control and Prevention have projected increases in the global incidence of tuberculosis of 36 and $58 \%$ in 2000 and 2005, respectively, compared with that of 1990 [1, 2]. Thus, this returned killer is likely to continue to pose a major health problem for the world in the next decade. In addition to the overall numerical increase in cases, the prevalence of drug-resistant tuberculosis is either increasing or still a cause for concern in many parts of the world [3-6]. It is the intention of this article to review the background, basic mechanisms and epidemiology of drug-resistant tuberculosis, and current and future strategies in management.

\section{Basic mechanisms and epidemiology of drug resistance}

Drug resistance in Mycobacterium tuberculosis occurs by random, single-step spontaneous mutations at the gene loci of the chromosomes, at a low but predictable frequency. Clinically drug-resistant tuberculosis arises slowly, usually as a result of selection pressure exerted by inadequate therapy. Resistance to one drug is not simultaneously associated or linked with another unrelated drug. However, cross-resistance among members of a similar class, such as the rifamycins and fluoroquinolones, does occur and has significant therapeutic implications. Mutations causing drug resistance in $M$. tuberculosis can alter one or more genes involved in effective drug action, affecting the primary drug target or the transport system. They may also cause increased synthesis of the target enzyme; thus, rendering the drug less effective to inhibit mycobacterial growth [7].

The probability of incidence of drug-resistant mutants is depicted by the formula: $\mathrm{P}=1-(1-\mathrm{r})^{\mathrm{n}}$, where $\mathrm{P}$ is the probability of incidence of drug-resistant cases, $r$ is the probability of incidence of drug-resistant mutants, and $n$ is the number of bacilli in the lesion [8]. The value of $\mathrm{r}$ for rifampicin is $10^{-8}$, that for isoniazid, streptomycin, ethambutol, kanamycin and para-aminosalicylic acid is $10^{-6}$, and that for ethionamide, capreomycin, cycloserine and thiacetazone is $10^{-3}[7,8]$. When two drugs are considered simultaneously, the value of $r$ becomes the product of the two individual rs, say $10^{-12}$ or $10^{-14}$. When three drugs are considered simultaneously, the value of $r$ becomes very low indeed, say $10^{-18}$ or $10^{-20}$. Thus, the probability of incidence of drug-resistant cases can be extremely minimal, or in fact practically nil, when three effective drugs are used for treatment in combination $[8,9]$.

The number of bacilli (n) in the lesion also influences the probability of drug-resistance, as shown by the earlier 
formula. Cavitary lesions usually contain from $10^{8}$ to $10^{9}$ organisms, but based on the aforementioned premise, drug resistance will not take place when three drugs are utilized together $[8,9]$.

Basically, drug resistance can be further categorized into initial resistance, primary resistance and acquired resistance [9].

Initial resistance is defined as the presence of drug resistance to one or more drugs in a new patient with tuberculosis presenting for treatment. This category includes patients with primary resistance, as well as those patients with undisclosed acquired resistance, who either cannot recall or who conceal prior therapy.

Primary resistance is defined as resistance to antituberculosis drugs in a patient who has never received chemotherapy. It can be caused by infection with drugresistant organisms from another patient with acquired resistance, or because of infection with naturally resistant wild mutants. For the purposes of this review, the term initial resistance is preferred, as it is often difficult to differentiate primary from undisclosed acquired resistance.

Acquired resistance is defined as resistance to antituberculosis drugs which arises as a result of poor adherence to the recommended regimen or poor prescribing. Emergence of acquired resistance in a patient often leads to treatment failure. Multidrug resistance refers to resistance to more than one antituberculosis drug, and is usually defined as resistance to isoniazid and rifampicin [6, 9].

A high initial resistance rate results from an inefficient national tuberculosis control programme in the past, but a high acquired resistance rate is more likely to represent a poorly functioning national tuberculosis control programme currently in operation [6]. Poor patient compliance is the most common cause for treatment failure and invites the development of drug resistance. Other causes of drug-resistant tuberculosis include inadequate therapy, in particular monotherapy, addition of a single agent to a failing regimen (the addition phenomenon), suboptimum drug dosages, and poor absorption [10-15].

In addition to these patient and physician related factors, there are other issues that may lead to emergence of drug resistance in the management of tuberculosis patients. The first category is related to administrative shortcomings in drug purchase and distribution. These problems may be either quantitative or qualitative, or both, and are especially prevalent in the developing countries [16, 17]. The second category is related to unsatisfactory standards of the pharmaceutical industry. Concern has been raised about the production and marketing of some substandard combined drug formulations with poor bioavailability of the component agents for the treatment of tuberculosis [18]. It is, therefore, crucial to subject all such combinations to stringent bioavailability studies before recommending their use in treatment of tuberculosis [19].

Thus, epidemiologically, several important factors have been found to contribute to the increased risk of drug resistance in general. These include history of previous therapy, birth or recent residence in areas with high prevalence of disease due to resistant bacilli, recent exposure to drug-resistant disease, and cavitary disease [13, 20, 21].

The frequency of initial drug resistance to one or more antituberculosis drugs is estimated to be $1-5 \%$ in some European countries, whilst the rates are substantially higher in countries in Africa (5-90\%), the Eastern Mediterranean (15-45\%) and South East Asia (15-80\%) $[6,22]$. In the USA, taking aside the methodological differences utilized in the assessment of initial drug resistance in the surveys, there has been some suggestion of a rise of definite magnitude of this index over the last three decades [4, 23]. Preliminary data from Centers for Disease Control also revealed that for the first quarter of 1991 , about $3.1 \%$ of new and $6.9 \%$ of recurrent cases were resistant to rifampicin and isoniazid [3]. In New York City, a recent report noted an initial drug resistance rate of $23 \%$, and an acquired drug resistance rate of $44 \%$ to one or more of the standard drugs [24].

\section{Impact of human immunodeficiency virus (HIV)-infection and social factors}

Globally, more than 4 million people are estimated to be co-infected with HIV and M. tuberculosis [25]. Concurrent with this upsurge of co-infection of HIV and tuberculosis is the emergence of drug-resistant tuberculosis, usually multidrug-resistant (MDR-TB) [26, 27]. Before 1990, there were several outbreaks of drug-resistant tuberculosis in the USA. These were outbreaks with relatively slow propagation, involving families, schools and the community [28-31]. Recently, however, a number of institution-based outbreaks of MDR-TB, with the majority of involved subjects infected with HIV, have taken place in the USA. The mortality was found to be very high (often amounting to $80 \%$ ) and death of patients occurred within a short time after diagnosis (median 4-16 weeks). Furthermore, transmission of MDR-TB among contacts tended to occur very quickly. These included patients, prison guards and health-care workers [32-36].

It is of great importance to realize that contrary to previous belief, drug-resistant organisms are as virulent and infectious as their drug-susceptible counterparts, and these are liable to be transmitted from the source patient to the contact, resulting in exogenous infection [37]. When the contact happens to be an HIV-infected subject, active progression to overt clinical tuberculosis results after exogenous infection, in a similar fashion to reactivation of an old focus. The scenario is worsened by this accelerated disease progression; thus, rapidly furnishing another new exogenous source of infection. A wildfire type of catastrophic spread of these MDR-TB infections in nosocomial or closely similar congregational settings might thus occur. Furthermore, factors have been identified that possibly enhance the rapidity of spread of infection among patients and health-care providers in these outbreaks. These include delay in diagnosis of tuberculosis, delay in recognition of drug resistance with resultant utilization of ineffective initial drug regimens, failure to 
strictly observe the recommended isolation precautions, including the lack of appropriate negative-pressure ventilation in the isolation rooms [34, 35]. Consequently, it appears that the guidelines issued by Centers for Disease Control and Prevention with the view to prevention of transmission of tuberculosis in health-care settings, with particular focus on HIV-related issues, should be implemented rapidly [38]. However, some of these guidelines and recommendations might be regarded as sophisticated and extreme in the UK and other European countries [15, 39]. Besides HIV-infected individuals, homeless subjects, alcoholics and intravenous drug abusers also have higher prevalence of drug resistance [4042]. The common contributory factor is likely to be noncompliance of drug therapy. The spread of disease is enhanced by close contact, such as accommodation in big shelters.

\section{Laboratory methods for rapid detection of drug-resistance}

At the moment, conventional culture and susceptibility studies using solid media require about 7 weeks [43], and are too slow to provide guidance for drug therapy in MDR-TB. The BACTEC radiometric system, which basically relies on the release of ${ }^{14} \mathrm{CO}_{2}$ from metabolizing mycobacteria, was found to be useful in providing drugsusceptibility results more rapidly, i.e. within about 3 weeks $[44,45]$. In essence, a qualitative technique similar to the proportion method for conventional susceptibility studies using solid media is used to identify drug resistance. If the growth on a drug-containing medium inoculated with $10^{2}$ dilution is greater than the growth on a drug-free medium inoculated with a $10^{4}$ dilution, then the strain is considered to be resistant [44]. Minimal inhibitory concentrators (MICs) of drugs and the effects of different drug combinations on mycobacteria can also be readily determined with the BACTEC procedure [46]. The radiometric method was compared with the conventional procedure for its ability to detect resistant strains to antituberculosis drugs. The correlation was found to be better for multiple-drug-resistant strains [47]. At present, standardized methods and reagents for testing only five of the antituberculosis drugs (streptomycin, rifampicin, isoniazid, ethambutol and pyrazinamide) are commercially available for use in the BACTEC system. Additional antituberculosis drugs can be tested, but testing entails preparation of appropriate dilutions of the drugs to be prepared by the individual laboratories [45].

The next new strategic development in rapid assessment of drug resistance springs from understanding of the molecular biology of MDR organisms. Firstly, there is a possibility of identification of mutated genes. It has been demonstrated that rifampicin resistance is brought about by mutations of the gene encoding the $\beta$-subunit of ribonucleic acid (RNA) polymerase. Rapid identification of rifampicin-resistant mutants is made possible by polymerase chain reaction single-stranded conformation polymorphism, within one day [48]. The analogous setting for isoniazid resistance is less favourable. This is because, although deletion of the Kat $\mathrm{G}$ gene that encodes a catalase-peroxidase enzyme was reported as a mechanism of producing isoniazid resistance [49], a number of clinically common isoniazid-resistant strains were found to have the Kat $\mathrm{G}$ gene [50]. Therefore, other genes might be responsible for isoniazid resistance, and it seems that multigenic assays may be required for clinical use.

Secondly, based on the observation that deoxyribonucleic acid (DNA) fingerprints of M. tuberculosis do not change during the development of drug resistance [51], restriction fragment length polymorphism (RFLP) analysis, using insertion element IS986-/IS6110-based DNA probe in particular, can be useful in epidemiological studies in MDR-TB outbreaks [52]. These RFLP patterns derived from patients in an outbreak can allow drug resistance to be simultaneously identified, and, thus, the analysis would be potentially useful for guiding the correct choice of antituberculosis drugs in these difficult-to-treat infections. The utility of these RFLP patterns of isolates from patients have been precisely reported in a number of outbreaks [34, 35].

A novel and most ingenious approach of assessing antimicrobial susceptibilities for MDR-TB organisms has been described to be the luciferase reporter phage [53, 54]. This test appears to be both sensitive and specific. It employs a mycobacteriophage, into which a cloned gene that encodes the luciferase that makes fireflies glow has been inserted. The production of light reveals presence of viable mycobacteria in the specimen, and a "turn-off-the-light" assay has been developed for detection of drug susceptibilities rapidly, within 3 days. However, further validation must be undertaken before the method can be extended for utilization in the clinical setting.

There are clearly problems in trying to apply these new techniques in developing countries, the constraints being both technological and financial. In the economically intermediate countries, the utility of the BACTEC system for selected cases can be considered. A slide culture sensitivity test system, giving results of susceptibilities in about 7 days, might also warrant further investigation under clinical settings in these countries [55].

\section{Chemotherapy for drug-resistant tuberculosis}

For patients without suspected drug resistance, a 6 month regimen, with an initial phase of daily isoniazid, rifampicin and pyrazinamide for 2 months, followed by a continuation phase of isoniazid and rifampicin for 4 months, has been recommended by the American Thoracic Society and the International Union Against Tuberculosis $[56,57]$. In populations with a high rate of initial drug resistance, it would be prudent to add a fourth drug for the initial phase of the regimen, namely ethambutol or streptomycin $[57,58]$. Where MDR-TB is common, initial regimens should be based on local surveillance data on drug susceptibilities [59, 60].

For patients who are subsequently known to have organisms resistant to streptomycin, there would obviously be no unfavourable sequelae using the initial regimens 
just described. For patients with isoniazid-resistant tuberculosis, there can be two possible approaches. Firstly, a modification of the initial three drug regimen, viz isoniazid, rifampicin and pyrazinamide, is made after 2 months of treatment by either continuation with therapy with rifampicin, pyrazinamide and ethambutol for another 10 months, or with rifampicin and ethambutol for a minimal period of 12 months [59, 61, 62]. Secondly, no modification of the initially administered modern four drug short-course chemotherapeutic regimen is required. There has also been suggestion that patients with organisms with dual resistance to streptomycin and isoniazid can be so managed without significant risk of chemotherapy failure [63, 64]. When patients already have known isoniazid-resistant disease, a 9 month regimen comprising streptomycin, rifampicin, pyrazinamide and ethambutol for 2 months, followed by rifampicin and ethambutol for 7 months, has also been shown to be effective [65]. On the other hand, for patients with isolated rifampicin-resistant tuberculosis, which is rare in the clinical setting, recommendation has been made to treat with isoniazid, pyrazinamide and ethambutol for 18-24 months. For HIV-infected subjects harbouring isoniazid-resistant organisms, continuation therapy of rifampicin and ethambutol up to 18 months has been suggested. For HIV-infected subjects with rifampicinresistant tuberculosis, a recommendation similar to that for the non-HIV-infected subjects has been made [66].

When MDR-TB is anticipated or considerably likely, a total of 5 or 6 drugs is recommended to be included in the initial treatment regimen This clinical situation should be anticipated in the following at-risk patient groups: 1) those in hospitals or health-care facilities known to be experiencing outbreaks of MDR-TB; 2) those from geographic regions where MDR-TB is common; and 3) those known to be at risk for MDR-TB, such as HIV-infected patients, intravenous drug abusers or the homeless $[13,58]$. When patients have established MDR-TB, the treatment outcomes are usually poor. One large series reported in the USA was concerned with presumably non-HIV-infected patients treated between 1973 and 1983 . The overall response rate was only $56 \%$ and the mortality was $37 \%$, despite the fact that all patients received a median of four drugs [12]. Drugs available for use for that period included amikacin, capreomycin, kanamycin, viomycin, clofazimine, cycloserine, ethionamide and pyrazinamide, in addition to the five conventional agents utilized in short-course chemotherapy viz streptomycin, ethambutol, rifampicin, isoniazid and pyrazinamide.

Para-aminosalicylic acid, ethionamide and cycloserine are time-honoured second-line antituberculosis drugs. They are usually noted for their poor tolerance by patients [14]. Amikacin and kanamycin share a similar chemical structure, and, thus, cross-resistance between these two compounds is relatively common [13, 67].

However, cross-resistance between these two compounds and streptomycin is rare [13]. Cost of amikacin is, however, much higher than kanamycin, and, thus, the latter is preferred whenever applicable [67]. Although there has been some controversy on the specific in vivo antimycobacterial activity of amikacin [13, 67], it is still listed as a potentially useful agent for management of MDR-TB [13]. Capreomycin is, however, only partially cross-resistant with amikacin and kanamycin, and might be useful under circumstances when cross-resistance does not exist [13, 67].

The fluoroquinolones are a group of antibacterial agents that have a possible pivotal role in the treatment of MDRTB. At present, such in vivo experience has been most favourable with ofloxacin [13, 68-70]. The experience with ciprofloxacin with regard to MDR-TB is much more limited, although the in vivo efficacy against M. tuberculosis has been somewhat ascertained [71]. More recently, sparfloxacin and levofloxacin have been found to have even more favourable MICs against $M$. tuberculosis in vitro $[72,73]$. Moreover, the in vivo activities of these two compounds as assessed in the experimental murine model have also been encouraging [74, 75]. However, the phenomenon of cross-resistance to the quinolones amongst the highly resistant $M$. tuberculosis strains can pose a therapeutic problem $[73,76]$. It has, in fact, been suggested that the use of quinolones in the treatment of multidrug-resistant tuberculosis might be more difficult than originally thought, and unsuccessful treatment of these infections with drugs from this class may jeopardize the efficacy of new class members not yet released for clinical use [76]. Thus, great prudence should be exercised in the prescription of quinolonecontaining drug regimens for treatment of MDR-TB.

Rifabutin, a derivative of rifamycin-S has been found to be active against $M$. tuberculosis in vitro. However, for rifampicin-resistant strains the MICs were found to be much higher, indicating cross-resistance between the two compounds [77]. The data concerning in vivo activity of rifabutin have been somewhat conflicting [7881]. The most likely cause of the discrepancy, apart from inherent susceptibilities of the strains in question, might be related to the design of the study. One study giving favourable results included fluoroquinolone in the regimens that the patients received [81].

Amoxycillin-clavulanic acid combination was found to have favourable in vitro activity against $M$. tuberculosis $[82,83]$. More recent in vitro data, however, have shown much higher MICs for this $\beta$-lactam- $\beta$-lactamase inhibitor against $M$. tuberculosis $[13,84]$. One anecdotal report of successful treatment of two MDR-TB cases by such a drug combination has appeared earlier in literature [83]. A subsequent report on more cases vindicates guarded optimism [84]. Clofazimine, the antileprosy agent has distinct activity against Mycobacterium aviumintracellulare [85]. However, its place in the management of MDR-TB requires further delineation [13]. The in vitro activity of macrolides, viz clarithromycin and roxithromycin, against $M$. tuberculosis have been discouraging when the MICs obtained for most strains studied were compared with the peak serum levels achievable for these drugs [73, 86, 87]. However, as macrolides are concentrated within lung tissues and alveolar macrophages [88], studies using macrophage cell lines might give more valid information on the activity of this class of compounds. 
The potential adverse reactions of the second-line old and new antituberculosis drugs have been summarized previously $[11,13]$. Most of these are well-known, such as ototoxicity and nephrotoxicity for amikacin, kanamycin and capreomycin. Of further interest is the potential interactive toxicity of drugs used to treat MDR-TB. One such example is the toxicity of cycloserine and ofloxacin on the central nervous system [89]. Rifabutin, in addition to an uncertain place in treatment of MDR$\mathrm{TB}$, has also been reported to cause adverse haematological reaction $[78,80]$.

The dosages of the drugs recommended for treatment of MDR-TB have been summarized previously $[11,13]$. Table 1 depicts dosages and adverse reactions of a number of antimicrobial agents that are of potential value in the treatment of this condition. There has been some suggestion, however, that ofloxacin would be therapeutically more effective when given as a single dose once daily $[69,70]$. Cycloserine or ethionamide is also more bactericidal when the total required daily dose of the drug is administered in two split portions per day, or once a day if tolerable [69, 70, 89]. More favourable outcomes might be anticipated in patients who manage to tolerate these scheduling manoeuvres. As for ciprofloxacin, the data concerning optimum dosage and frequency of administration have been rather limited.

The adequate duration of therapy for MDR-TB has not been clearly identified, because of difficulty of performing randomized clinical studies. The duration that has been recommended in the USA is $18-24$ months at least, or 24 months after sputum culture conversion from positivity to negativity for HIV-negative subjects. That recommended for HIV-positive subjects would be 24 months after sputum bacteriological conversion [13, 66]. Concerning the number of drugs required for treating confirmed MDR-TB, the minimal requirement would be at least three drugs to which the organisms are still susceptible [57, 62]. More drugs administered concomitantly, if tolerated, would be likely to be beneficial, and, thus, recommended $[13,69,70]$.

Finally, therapy for MDR-TB should be commenced in hospital, to allow monitoring of drug intolerance and toxicity. Compliance must be further enforced at this stage. Attention to attendant measures to contain the spread of disease within the hospital must be taken.

\section{Patient compliance and drug-resistant tuberculosis}

Noncompliance with therapy is the greatest problem in the control of tuberculosis. It can result in treatment failure and development of drug resistance. Compliance with antituberculosis chemotherapy involves several participants, each with a specific role to play. Notwithstanding this complex orchestra, the most important person remains the patient himself. Recognizing noncompliant

Table 1. - Dosages and adverse reactions of some potentially useful drugs for treatment of multidrug-resistant tuberculosis

\begin{tabular}{|c|c|c|c|}
\hline Name of drug & $\begin{array}{l}\text { Usual adult total } \\
\text { daily dosage* }\end{array}$ & \multicolumn{2}{|c|}{ Possible adverse reactions } \\
\hline Ethambutol & $\begin{array}{l}15-25 \mathrm{mg} \cdot \mathrm{kg}^{-1} \\
\text { (higher dose for } \\
\text { initial } 2 \text { months) }\end{array}$ & Asymptomatic hyperuricaemia & $\begin{array}{l}\text { Optic neuritis (often dose- } \\
\text { related), peripheral neuritis, } \\
\text { skin rash }\end{array}$ \\
\hline Pyrazinamide & $1.5 \mathrm{~g}-2.0 \mathrm{~g}$ & $\begin{array}{l}\text { Asymptomatic hyperuricaemia, } \\
\text { gastrointestinal disturbance, } \\
\text { arthralgia }\end{array}$ & $\begin{array}{l}\text { Clinical gout, hepatitis (often } \\
\text { dose-related), sideroblastic } \\
\text { anaemia }\end{array}$ \\
\hline Amikacin & $\begin{array}{l}15 \mathrm{mg} \cdot \mathrm{kg}^{-1} \\
(5 \times \text { a week })\end{array}$ & & Nephrotoxicity: deranged renal \\
\hline Kanamycin & $\begin{array}{l}15 \mathrm{mg} \cdot \mathrm{kg}^{-1} \\
(5 \times \mathrm{a} \text { week })\end{array}$ & $\begin{array}{l}\text { Ototoxicity: ataxia, vertigo, } \\
\text { hearing loss (usually dose- and } \\
\text { duration-related; also more } \\
\text { frequent in elderly patients) }\end{array}$ & $\begin{array}{l}\text { function biochemically, clinical } \\
\text { renal failure (usually dose- and } \\
\text { duration-related; also more } \\
\text { frequent in elderly patients) }\end{array}$ \\
\hline Capreomycin & $\begin{array}{l}15 \mathrm{mg} \cdot \mathrm{kg}^{-1} \\
(5 \times \text { a week })\end{array}$ & & \\
\hline Ofloxacin & $600-800 \mathrm{mg}$ & $\begin{array}{l}\text { \} Gastrointestinal disturbance, } \\
\text { insomnia }\end{array}$ & $\begin{array}{l}\text { Anxiety, headache, hand } \\
\text { tremor, seizure }\end{array}$ \\
\hline Ciprofloxacin & 750-1500 mg (?) & \} & \\
\hline Ethionamide & $750 \mathrm{mg}$ & $\begin{array}{l}\text { Anorexia, nausea, metallic taste in } \\
\text { mouth, vomiting, depression }\end{array}$ & $\begin{array}{l}\text { Convulsion, peripheral neuritis, } \\
\text { hepatitis }\end{array}$ \\
\hline Cycloserine & $750 \mathrm{mg}$ & $\begin{array}{l}\text { Depression, memory loss, } \\
\text { headache, irritability, paranoid and } \\
\text { catatonic reaction }\end{array}$ & $\begin{array}{l}\text { Severe psychosis, convulsion, } \\
\text { sideroblastic anaemia }\end{array}$ \\
\hline $\begin{array}{l}\text { Para-aminosalicylic } \\
\text { acid (PAS) }\end{array}$ & $10-12 \mathrm{~g}$ & Nausea, bloating and diarrhoea & $\begin{array}{l}\text { Drug fever, hypothyroidism, } \\
\text { hepatitis, blood dyscrasia } \\
\text { including haemolysis }\end{array}$ \\
\hline
\end{tabular}

*: dosages assuming normal hepatic and renal function. 
behaviour is more easily said than done. It seems that introducing ways of reduction of noncompliance would be logical and more cost-effective. But the most important means of ensuring compliance is, in fact, the implementation of directly observed therapy (DOT), which can be achieved with daily, twice weekly or thrice weekly administration of medication with presently available regimens [57, 58, 90, 91]. Even high-risk groups for noncompliance, such as homeless individuals and patients with drug-resistant disease, have responded to such therapy [92, 93]. Organization of DOT and comprehensive services certainly have significant financial implications, but the cost of treating patients with MDR-TB even in small numbers is enormously larger [3, 91].

\section{Other modalities of therapy for drug-resistant tuberculosis}

\section{Surgery}

Surgical resection of diseased lung as an adjunct to medical therapy can be employed in patients with drugresistant tuberculosis. This would be the indication mainly in patients receiving unsatisfactory drug regimens due to lack of active drugs found from in vitro susceptibility tests, and in patients with destroyed lung parenchyma and/or empyema where drug penetration can be problematical. Patients with sufficiently localized disease and expectation of adequate postsurgery cardiopulmonary capacity are most suitable. The outcomes have been found to be rewarding in experienced hands [94, 95]. Nevertheless, the risk of postoperative bronchial fistula formation, which can be associated with significant morbidity and even mortality especially in patients with high bacillary load, should be borne in mind.

\section{Immunotherapy}

For some time, cytokines have been suspected to have a role in the immunoregulation and pathogenesis of tuberculosis. Furthermore, there has been some evidence that the imbalance of profiles of cytokines, or qualitative alteration of cytokine toxicity to tissues which are rendered susceptible, may be responsible for the different types of immunological response to $M$. tuberculosis. The Koch phenomenon has traditionally been viewed as a destructive type of immunological reaction resulting in caseous necrosis in histopathology. The other alternative type of cell-mediated response has now been regarded as a protective immunity $[96,97]$. Thus, if it is possible to provide a switch of cytokine profile, a protective immunity might be established [98]. Mycobacterium vaccae, a saprophytic mycobacterial species, when killed by autoclaving and made into a vaccine (NCTC-11659), might be able to confer protective immunity by such a postulated mechanism, following the recognition of the common mycobacterial antigen that is non-species specific and shared between the slow-growers, the fast-growers and the non-cultivable mycobacteria by the host's immune system [97, 98]. A few preliminary anecdotal reports have shown some usefulness of this type of immunotherapy in patients with drug-resistant tuberculosis in Africa, Vietnam, Iran and Romania [98-100]. However, clearly, much more effort is required to delineate the specific role of $M$. vaccae immunotherapy in MDR-TB.

In conclusion, tuberculosis, once the white plague, is about to return, which is, in many countries, due to the declining infrastructure both of tuberculosis control and treatment programmes [3]. In many developing countries, in Africa and in Asia, only incomplete tuberculosis programmes are in existence. Amongst countries in these two continents where tuberculosis control programmes have been successfully implemented with the modern short-course chemotherapy, the outcomes have been quite favourable and drug-resistance rates have substantially declined or are expected to decline [101, 102]. Thus, to combat tuberculosis, and in particular, its most serious form, viz drug-resistant tuberculosis, establishment or resurrection of a good national tuberculosis control programme leaves no time for complacency. The potential threat of the upsurge of drug-resistant tuberculosis in the face of the HIV epidemic that has exploded in Africa, and will probably do so in some countries of Asia [103] in the near future, should provide the strongest impetus for such programme development or reinforcement by government health authorities.

\section{References}

1. Dolin PJ, Raviglione MC, Kochi A. Global tuberculosis incidence and mortality during 1990-2000. Bull WHO 1994; 72: 213-220.

2. Centers for Disease Control and Prevention. Estimates of future global tuberculosis morbidity and mortality. Morb Mort Weekly Rep 1993; 42: 961-964.

3. Bloom BR, Murray CJL. Tuberculosis: commentary on a re-emergent killer. Science 1992; 257: 1055-1064.

4. Snider DE Jr, Cauthen GM, Farer LS, et al. Drugresistant tuberculosis. Am Rev Respir Dis 1991; 144: 732.

5. Villarino ME, Geiter LJ, Simone PM. The multidrugresistant tuberculosis challenge to public health efforts to control tuberculosis. Public Health Rep 1992; 107: 616-625.

6. Kochi A, Vareldzis B, Styblo K. Multidrug-resistant tuberculosis and its control. Res Microbiol 1993; 144: 104-110.

7. Rastogi N, David HL. Mode of action of antituberculous drugs and mechanisms of resistance in Mycobacterium tuberculosis. Res Microbiol 1993; 144: 133-143.

8. Shimao T. Drug resistance in tuberculosis control. Tubercle 1987; 68 (Suppl.): S5-15.

9. Vareldzis BP, Grossset J, de Kantor I, et al. Drugresistant tuberculosis: laboratory issues. World Health Organization recommendations. Tubercle Lung Dis 1994; 75: $1-7$.

10. Crofton J. The prevention and management of drugresistant tuberculosis. Bull Int Union Tuberc Lung Dis 1987; 62: 6-11.

11. Iseman MD, Madsen LA. Drug-resistant tuberculosis. Clin Chest Med 1989; 10: 341-353. 
12. Goble M, Iseman MD, Madsen LA, Waite D, Ackerson L, Horsburgh CR Jr. Treatment of 171 patients with pulmonary tuberculosis resistant to isoniazid and rifampicin. N Engl J Med 1993; 328: 527-532.

13. Iseman MD. Treatment of multidrug-resistant tuberculosis. N Engl J Med 1993; 329: 784-791.

14. Mahmoudi A, Iseman MD. Pitfalls in the care of patients with tuberculosis: common errors and their association with the acquisition of drug resistance. $\mathrm{J} \mathrm{Am} \mathrm{Med}$ Assoc 1993; 270: 65-68.

15. Uttley AHC, Pozniak A. Resurgence of tuberculosis. $J$ Hosp Infect 1993; 23: 249-253.

16. Fox W. Tuberculosis in India, past, present and future. Ind J Tuberc 1990; 37: 175-213.

17. Gangadharam PRJ. Drug resistance in tuberculosis: it's not always the patient's fault! Tubercle Lung Dis 1993; 74: 65-66.

18. Fox W. Drug combinations and the bioavailability of rifampin. Tubercle 1990; 71: 241-245.

19. Ellard GA, Ellard DR, Allen BW, et al. The bioavailability of isoniazid, rifampicin and pyrazinamide in two commercially available combined formulations designed for use in the short-course treatment of tuberculosis. Am Rev Respir Dis 1986; 133: 1076-1080.

20. Davidson PT. Drug resistance and selection of therapy for tuberculosis. Am Rev Respir Dis 1987; 136: 255257.

21. Riley LW, Arathoon E, Loverde VD. The epidemiologic patterns of drug-resistant Mycobacterium tuberculosis infections: a community-based study. Am Rev Respir Dis 1989; 139: 1282-1285.

22. World Health Organization. Laboratory evaluation of drug resistant tuberculosis. Document WHO/TB/93.171. Geneva, World Health Organization, 1993.

23. Centers for Disease Control. Primary resistance to antituberculosis drugs: United States. Morb Mort Weekly Rep 1983; 32: 521-523.

24. Frieden TR, Sterling T, Pablos-Mendez A, Kilburn JO, Cauthen GM, Dooley SW. The emergence of drugresistant tuberculosis in New York City. $N$ Engl J Med 1993; 328: 521-526.

25. Narain JP, Raviglione MC, Kochi A. HIV-associated tuberculosis in developing countries: epidemiology and strategy for prevention. Tubercle Lung Dis 1992; 73: 311-321.

26. Centers for Disease Control and Prevention. National action plans to combat multidrug-resistant tuberculosis. Morb Mort Weekly Rep 1992; 41 (RR-11): 5-48.

27. Centers for Disease Control and Prevention. Meeting the challenge of multidrug-resistant tuberculosis. Summary of a conference. Morb Mort Weekly Rep 1992; 41 (RR-11): 51-57.

28. Steiner M, Chaves AD, Lyons HA, Steiner P, Portugaleza C. Primary drug-resistant tuberculosis: report of an outbreak. N Engl J Med 1970; 283: 1353-1358.

29. Centers for Disease Control. Interstate outbreak of drugresistant tuberculosis involving children: California, Montana, Nevada, Utah. Morb Mort Weekly Rep 1983; 32: 516-518.

30. Reves R, Blakey D, Snider DE Jr, Farer LS. Transmission of multiple drug-resistant tuberculosis: report of a school and community outbreak. Am J Epidemiol 1981; 113: 423-435.

31. Centers for Disease Control. Drug-resistant tuberculosis among the homeless: Boston. Morb Mort Weekly Rep 1985; 34: 429-431.

32. Centers for Disease Control and Prevention. Nosocomial transmission of multidrug-resistant tuberculosis among HIV-infected persons: Florida and New York 1988-1991. Morb Mort Weekly Rep 1991; 40: 585-591.

33. Centers for Disease Control and Prevention. Transmission of multidrug-resistant tuberculosis from an HIVpositive client in a residential substance-abuse treatment facility: Michigan. Morb Mort Weekly Rep 1991; 40: 129-131.

34. Pearson ML, Jereb JA, Frieden TR, et al. Nosocomial transmission of multidrug-resistant Mycobacterium tuberculosis: a risk to patients and health-care workers. Ann Intern Med 1992; 117: 191-196.

35. Beck-Sague C, Dooley SW, Hutton MD, et al. Hospital outbreak of multidrug-resistant Mycobacterium tuberculosis infections: factors in transmission to staff and HIV-infected patients. J Am Med Assoc 1992; 268: 1280-1286.

36. Fischl MA, Uttamchandani RB, Daikos GL, et al. An outbreak of tuberculosis caused by multiple-drug-resistant tubercle bacilli among patients with HIV infection. Ann Intern Med 1992; 117: 177-183.

37. Snider DE Jr, Kelly GD, Cauthan GM, Thompson NJ, Kilburn JO. Infection and disease among contacts of tuberculosis cases with drug-resistant and drug-susceptible bacilli. Am Rev Respir Dis 1985; 132: 125-132.

38. Dooley SW, Castro KG, Hutton MD, Mullan RJ, Polder JA, Snider DE Jr. Guidelines for preventing the transmission of tuberculosis in health-care settings with special focus on HIV-related issues. Morb Mort Weekly Rep 1990; 39: (RR-17): 1-29.

39. A joint statement of the International Union Against Tuberculosis and Lung Disease (IUATLD) and the Tuberculosis Programme of the World Health Organization (WHO). Control of tuberculosis transmission in health care settings. Tubercle Lung Dis 1994; 75: 94-95.

40. Brudney K, Dobkin J. Resurgent tuberculosis in the New York City. Am Rev Respir Dis 1991; 144: 745-749.

41. Morris JT, McAllister CK. Homeless individuals and drug-resistant tuberculosis in South Texas. Chest 1992; 102: 802-804.

42. Selwyn PA, Sckell BM, Alcabes P, Friedland GH, Klein RS, Schoenbaum EE. High risk of active tuberculosis in HIV-infected drug users with cutaneous anergy. $\mathrm{J} \mathrm{Am}$ Med Assoc 1992; 268: 504-509.

43. Levy H, Feldman C, Sacho H, van der Meulen J, Kallenbach J, Koornhof H. A re-evaluation of sputum microscopy and culture in the diagnosis of pulmonary tuberculosis. Chest 1989; 95: 1193-1197.

44. Good RC, Mastro TD. The modern mycobacteriology laboratory. How it can help the clinician? Clin Chest Med 1989; 10: 315-322.

45. Huebner RE, Good RC, Tokars JI. Current practices in mycobacteriology: results of a survey of state public health laboratories. J Clin Microbiol 1993; 31: 771775 .

46. Heifets L. Qualitative and quantitative drug-susceptibility tests in mycobacteriology. Am Rev Respir Dis 1988; 137: $1217-1222$

47. Snider DE Jr, Good RC, Kilburn JO, et al. Rapid drugsusceptibility testing of Mycobacterium tuberculosis. Am Rev Respir Dis 1981; 123: 402-406.

48. Telenti A, Imboden P, Marchesi F, et al. Detection of rifampicin-resistance mutations in Mycobacterium tuberculosis. Lancet 1993; 341: 647-650.

49. Zhang J, Heym B, Allen B, Young D, Cole S. The catalase-peroxidase gene of Mycobacterium tuberculosis. Nature 1992; 358: 591-593. 
50. Stoeckle MY, Guan L, Riegler N, et al. Catalaseperoxidase gene sequences in isoniazid-sensitive and resistant strains of Mycobacterium tuberculosis from New York City. J Infect Dis 1993; 168: 1063-1065.

51. Godfrey-Faussett P, Stoker NG, Scott JAG, Pasvol G, Kelly P, Clancy L. DNA fingerprints of Mycobacterium tuberculosis do not change during the development of rifampicin resistance. Tubercle Lung Dis 1993; 74: 240-243.

52. Hermans PWM, van Soolingen D, Dale JW, et al. Insertion element IS986 from Mycobacterium tuberculosis: a useful tool for diagnosis and epidemiology of tuberculosis. J Clin Microbiol 1990; 28: 2051-2058.

53. Jacobs WR Jr, Barletta RG, Udani R, et al. Rapid assessment of drug susceptibilities of Mycobacterium tuberculosis by means of luciferase reporter phages. Science 1993; 260: 819-822.

54. Cooksey RC, Crawford JT, Jacobs WR Jr, Shinnick TM. A rapid method for screening antimicrobial agents for activities against a strain of Mycobacterium tuberculosis expressing firefly luciferase. Antimicrob Agents Chemother 1993; 37: 1348-1352.

55. Dickinson JM, Allen BW, Mitchison DA. Slide culture sensitivity tests. Tubercle 1989; 70: 115-121.

56. American Thoracic Society. Treatment of tuberculosis and tuberculosis infection in adults and children. $A m$ Rev Respir Dis 1986; 134: 355-363.

57. Recommendations from the Committee on Treatment of the International Union Against Tuberculosis and Lung Disease. Antituberculosis regimens of chemotherapy. Bull Int Union Tuberc Lung Dis 1988; 63: 60-64.

58. Centers for Disease Control and Prevention. Initial therapy for tuberculosis in the era of multidrug-resistance: recommendations of the Advisory Council for the Elimination of Tuberculosis. Morb Mort Weekly Rep 1993; 42: $1-8$.

59. Barnes PF. Tuberculosis in the 1990s. Ann Intern Med 1993; 119: 400-410.

60. Nunn P, Felten M. Surveillance of resistance to antituberculosis drugs in developing countries. Tubercle Lung Dis 1994; 75: 163-167.

61. Davidson PT. Drug resistance and selection of therapy for tuberculosis. Am Rev Respir Dis 1987; 136: 255-257.

62. Subcommittee of the Joint Tuberculosis Committee, British Thoracic Society. Chemotherapy and management of tuberculosis in the United Kingdom: recommendations of the Joint Tuberculosis Committee of the British Thoracic Society. Thorax 1990; 45: 405-408.

63. Mitchison DA, Nunn AJ. Influence of initial drug resistance on the response to short-course chemotherapy of pulmonary tuberculosis. Am Rev Respir Dis 1986; 133: 423-430.

64. Hong Kong Chest Service/British Medical Research Council. Controlled trial of 2, 4 and 6 months of pyrazinamide in 6 months three times weekly regimens for smear-positive pulmonary tuberculosis including an assessment of a combined preparation of isoniazid, rifampicin and pyrazinamide. Am Rev Respir Dis 1991; 143: 700-706.

65. Swai OB, Aluoch JA, Githui WA, Thiong'o R, Edwards EA. Controlled clinical trial of a regimen of two durations for the treatment of isoniazid resistant pulmonary tuberculosis. Tubercle 1988; 69: 5-14.

66. Barnes PF, Block AB, Davidson PT, Snider DE Jr. Tuberculosis in patients with human immunodeficiency virus infection. N Engl J Med 1991; 324: 1644-1650.

67. Allen BW, Mitchison DA, Chan YC, Yew WW, Allan
WGL. Amikacin in the treatment of pulmonary tuberculosis. Tubercle 1983; 64: 111-118.

68. Tsukamura M, Nakamura E, Yoshii S, Amano H. Therapeutic effect of a new antibacterial substance ofloxacin (DL8280) on pulmonary tuberculosis. Am Rev Respir Dis 1985; 131: 352-356.

69. Yew WW, Kwan SYL, Ma WK, Khin MA, Chau PY. In vitro activity of ofloxacin against Mycobacterium tuberculosis and its clinical efficacy in multiply resistant pulmonary tuberculosis. J Antimicrob Chemother 1990; 26: 227-236.

70. Yew WW, Wong PC, Lee J, Chau CH. Ofloxacin and pulmonary tuberculosis. Chest 1994; 105: 1624.

71. Gillespie SH, Ngowi FJ, Kennedy N, Uiso L. Role of ciprofloxacin in tuberculosis therapy. In: Shah PM, ed. Ciprofloxacin in Pulmonology. II. Muchen-Bern-Wein, New York, W. Zuckschwerdt Verlag, 1992; pp. 27-30.

72. Rastogi N, Goh KS. In vitro activity of the new difluorinated quinolone sparfloxacin (AT-4140) against Mycobacterium tuberculosis compared with activities of ofloxacin and ciprofloxacin. Antimicrob Agents Chemother 1991; 35: 1933-1936.

73. Yew WW, Piddock LJV, Li MSK, Lyon D, Chan CY, Cheng AFB. In vitro activity of quinolones and macrolides against mycobacteria. J Antimicrob Chemother 1994; 34: 343-351.

74. Lalande V, Truffot-Pernot C, Paccaly-Moulin A, Grosset J, Ji B. Powerful bactericidal activity of sparfloxacin (AT-4140) against Mycobacterium tuberculosis in mice. Antimicrob Agents Chemother 1993; 37: 407-413.

75. Klemens SP, Sharpe CA, Rogge MC, Cynamon MH. Activity of levofloxacin in a murine model of tuberculosis. Antimicrob Agents Chemother 1994; 38: 1476-1479.

76. Rastogi N, Ross BC, Dwyer B, et al. Emergence during unsuccessful chemotherapy of multidrug resistance in a strain of Mycobacterium tuberculosis. Eur J Clin Microbiol Infect Dis 1992; 11: 901-907.

77. Heifets LB, Iseman MD. Determination of in vitro susceptibility of mycobacteria to ansamycin. Am Rev Respir Dis 1985; 132: 710-711.

78. O'Brien RJ, Lyle MA, Snider DE Jr. Rifabutin (ansamycin LM-427). A new rifamycin-S derivative for the treatment of mycobacterial diseases. Rev Infect Dis 1987; 9: 519-530.

79. Gillespie SH, Baskerville AJ, Davidson RN, Felmingham $\mathrm{D}$, Bryceson ADM. The serum rifabutin concentrations in a patient successfully treated for multidrug-resistant Mycobacterium tuberculosis infection. J Antimicrob Chemother 1990; 25: 490-491.

80. Hong Kong Chest Service, British Medical Research Council. A controlled study of rifabutin and an uncontrolled study of ofloxacin in the retreatment of patients with pulmonary tuberculosis resistant to isoniazid, streptomycin and rifampicin. Tubercle Lung Disease 1992; 73: 59-67.

81. Pretet S, Lebeaut A, Parrot R, Truffot C, Grosset J, DinhXuan AT. Combined chemotherapy including rifabutin for rifampicin and isoniazid resistant tuberculosis. Eur Respir J 1992; 5: 680-684.

82. Cynamon MH, Palmer GS. In vitro activity of amoxycillin in combination with clavulanic acid against $\mathrm{Myco-}$ bacterium tuberculosis. Antimicrob Agents Chemother 1983; 24: 429-431.

83. Nadler JP, Berger J, Nord JA, Cofsky R, Saxena M. Amoxicillin-clavulanic acid for treating drug-resistant Mycobacterium tuberculosis. Chest 1991; 99: 10251026. 
84. Yew WW, Wong CF, Lee J, Wong PC, Chau CH. Do beta-lactam-beta-lactamase inhibitor combinations have a place in treatment of multidrug-resistant pulmonary tuberculosis? Tubercle Lung Dis 1995; 76: 90-92.

85. Lindholm-Levy PJ, Heifets LB. Clofazimine and other rimino-compounds: minimal inhibitory and minimal bactericidal concentrations at different $\mathrm{pHs}$ for $\mathrm{Myco-}$ bacterium avium complex. Tubercle 1988; 69: 179-186.

86. Casal M, Gutierrez J, Gonzalez J, Ruiz P. In vitro susceptibility of Mycobacterium tuberculosis to a new macrolide antibiotic, RU-28965. Tubercle 1987; 68: 141-143.

87. Rastogi N, Goh KS. Effect of $\mathrm{pH}$ on radiometric MICs of clarithromycin against 18 species of mycobacteria. Antimicrob Agents Chemother 1992; 36: 2841-2842.

88. Honeybourne D, Baldwin DR. The site concentrations of antimicrobials in the lung. J Antimicrob Chemother 1992; 30: 249-260.

89. Yew WW, Wong CF, Wong PC, Lee J, Chau CH. Adverse neurological reactions in patients with multidrug-resistant pulmonary tuberculosis after co-administration of cycloserine and ofloxacin. Clin Infect Dis 1993; 17: 288289.

90. Cohn DL, Catlin BJ, Peterson KL, Judson FN, Sbarbaro JA. A 62 dose, 6 month therapy for pulmonary and extrapulmonary tuberculosis: a twice-weekly, directly observed and cost-effective regimen. Ann Intern Med 1990; 112: 407-415.

91. Iseman MD, Cohn DL, Sbarbaro JA. Directly observed treatment of tuberculosis: we can't afford not to try it. N Engl J Med 1993; 328: 576-578.

92. McAdam JM, Brickner PW, Scharer LL, Crocco JA, Duff AE. The spectrum of tuberculosis in a New York City men's shelter clinic (1982-1988). Chest 1990; 97 : 798-805.
93. McDonald RJ, Memon AM, Reichman LB. Successful supervised ambulatory management of tuberculosis treatment failures. Ann Intern Med 1982; 96: 297-302.

94. Iseman MD, Madsen L, Goble M, Pomerantz M. Surgical intervention in the treatment of pulmonary disease caused by drug-resistant Mycobacterium tuberculosis. Am Rev Respir Dis 1990; 41: 623-625.

95. Mahmoudi A, Iseman MD. Surgical intervention in the treatment of drug-resistant tuberculosis: update and extended follow-up. Am Rev Respir Dis 1992; 145 (Suppl.): A816 (Abstract).

96. Rook GAW, Al Attiyah R. Cytokines and the Koch phenomenon. Tubercle 1991; 72: 13-20.

97. Stanford JL. Koch's phenomenon: can it be corrected. Tubercle 1991; 72: 241-249.

98. Stanford JL, Grange JM. New concepts for the control of tuberculosis in the twenty first century. $J R$ Coll Physicians (Lond) 1993; 27: 218-223.

99. Onyebujoh PC, Rook GAW, Stanford JL. Mycobacterium vaccae immunotherapy. Lancet 1991; 338: 1534.

100. Etemadi A, Farid R, Standord JL. Immunotherapy for drug-resistant tuberculosis. Lancet 1992; 340: 13601361.

101. Murray CJL, DeJonghe E, Chum HJ, Nyangulu DS, Salomao A, Styblo K. Cost-effectiveness of chemotherapy programmes for the control of pulmonary tuberculosis in three sub-Saharan African countries. Lancet 1991; 338: 1305-1308.

102. Kim SJ, Hong YP. Drug resistance of Mycobacterium tuberculosis in Korea. Tubercle Lung Dis 1992; 73: 219-224.

103. Murray CJL, Styblo K, Rouillon A. Tuberculosis in developing countries: burden, intervention and cost. Bull Int Union Tuberc Lung Dis 1990; 65: 6-24. 